\title{
AMOR E INGENIO DE MUJER: TÁCTICAS DE CERVANTES, PACHECO Y CALDERÓN FRENTE AL DESTINO
}

En cada lectura de las obras de Cervantes no deja de sorprendernos con qué rigor persigue la noción de libertad. Son muchos los pasajes donde formula toda una teoría de la libertad, recordemos uno de ellos, su diálogo con Apolo en el Viaje del Parnaso:

"Tú mismo te has forjado tu ventura, y yo te he visto alguna vez con ella, pero en el imprudente poco dura. Mas si quieres salir de tu querella, alegre, y no confuso, y consolado, dobla tu capa, y siéntate sobre ella. Que tal vez suele un venturoso estado, cuando le niega sin razón la suerte, honrar más merecido que alcanzado".

Cervantes reconoce la inevitable distancia entre la pretensión y la realidad, con la que debemos contar; pero la vida es deseo.

Y en este punto nos planteamos la siguiente cuestión: ¿era posible para la mujer del siglo XVII llevar a la práctica esa máxima de Cervantes de que nadie puede anular la libertad personal, aun con las trabas e impedimentos impuestos por una sociedad machista y misógina? ${ }^{1}$.

Creemos que sí era posible y lo vamos a comprobar a través del tratamiento del personaje femenino en tres autores: Cervantes ${ }^{2}$, Calderón y Luis Pacheco de Narváez.

1 Acerca de esa figura de mujer que desde el teatro del Renacimiento se va apoderando poco a poco de la escena vid. ROSA NAVARRO DURÁN, "El arte de fingirse boba y otras recreaciones: La boba para los otros y discreta para sín, FELIPE B. Pedraza Jiménez, ed., La década de oro de la comedia española, 1630-1640. Actas de las XIX Jornadas de Teatro Clásico. Almagro, Universidad Castilla-La Mancha, 1996, pp. 41-59. JOAN OLEZA, «Alternativas al gracioso: la dama donaire», Criticón, 60, 1994, pp. 35-48.

2 LUIS IGLESIAS FEIJOo, "Que hay mujeres tramoyeras": La "matemática per- 
Tomemos como ejemplo cervantino la novela («intercalada» en la primera parte del Quijote), que el cura lee en la venta, El curioso impertinente. En ésta, Anselmo, marido de Camila, es el interesado en violar la libertad de su esposa, al empecinarse en unos deseos compulsivos de poner a prueba la bondad y perfección de Camila ${ }^{3}$, empujándola a los brazos de Lotario, amigo inseparable de solteros.

Mas, Lotario advierte al marido "que la mujer es animal imperfecto, y que no se le han de poner embarazos donde tropiece y caiga, sino quitárselos y despejalle el camino de cualquier inconveniente, para que sin pesadumbre corra ligera a alcanzar la perfección que le falta, que consiste en el ser virtuosa».

Al abandonar Anselmo el domicilio para facilitar a Lotario su propósito, Camila le comunica en una carta que no puede sufrir esa ausencia. En ese momento estamos ante una mujer dolida porque se siente abandonada y por lo tanto insatisfecha. Sentimiento oculto quizás desde el principio de su matrimonio, que aflora a la vez que la siniestra conducta de Anselmo. Nuestra opinión viene reforzada en cierta manera por el argumento de Francisco Ayala sobre la relación entre los dos amigos; él opina que «Cervantes elabora con cuidado primoroso dicha relación, el débil y sensual Anselmo, supeditado siempre, y Lotario, el deportista, para hacernos asistir, tan pronto como la presencia de Camila ha roto el tenso equilibrio emocional de su amistad, a ese proceso enfermizo en que la trama de la novela consiste, y durante el cual pretenderá conseguir el nuevo esposo satisfacción vicaria a través de su mujer (carne de su carne en virtud del matrimonio) para los turbios deseos que hasta entonces había mantenido larvados o, mejor dicho, sublimados en las formas nobles de camaradería» ${ }^{4}$.

Cervantes sabe evitar lo que puedan parecer incongruencias mediante el genial recurso de llevar las motivaciones de Anselmo al plano subconsciente, haciendo que sus deseos sean inexplicables para su propia mente.

fecta" de la comedia calderoniana», Felipe B. PEdRAZA JimÉnEZ, ed., La comedia de enredo. Actas de las XX Jornadas de Teatro Clásico. Almagro, Universidad CastillaLa Mancha, 1998. Iglesias Feijoo en este interesante estudio de las comedias calderonianas, integrantes de un universo distinto de los dramas serios, asume que la literatura puede funcionar desligada de cualquier propósito moral directo. Tal punto de partida es el que se va desarrollando poco a poco a partir del Renacimiento, origen del mundo moderno, y Calderón - sugiere Iglesias- pudo hallar un defensor excepcional del mismo en su admirado Cervantes (p. 215).

3 Carmen CASTro, "Las mujeres del Quijote», Anales Cervantinos, tomo III, 1953, p. 72

4 Francisco Ayala, «Los dos amigos», ANa Rodríguez Fischer, ed., Miguel de Cervantes y los escritores del 27. Barcelona, Anthropos, julio-agosto 1989, pp. 37-44. 
Lotario cuando se da cuenta de que no se trata de un juego ya está perdidamente enamorado de Camila, pues como sentencia Sancho en el cap. VII de la 2. ${ }^{a}$ parte del Quijote, "el hombre ha de ser hombre, y la mujer, mujer». La obstinada insensatez de Anselmo provoca que despierte la atracción natural de la hermosa Camila, «porque si la lengua callaba, el pensamiento discurría» e inevitablemente acaba entregándose a los requerimientos del amigo de su esposo. Cervantes consciente de que el caso podía lesionar las expectativas convencionales de la época, se limita a dar noticia del comportamiento de Camila de manera sumaria en una sola frase, retóricamente reiterada: "Rindióse Camila; Camila se rindió».

$\mathrm{Y}$ nosotros podemos decir que Camila hizo uso de su libertad, condición intrínseca de la vida humana, resultando ese adulterio explicable en términos humanos, tal y como lo presenta Cervantes de acuerdo con su actitud, siempre clara a lo largo de toda su obra: el amor no se puede imponer, ni se puede impedir ni contrariar cuando es verdadero amor, la forma suprema de la libertad.

Ello justifica que Camila no se arrepienta de vivir su libertad cuando toma por confidente a su criada Leonela para expresarle su turbación únicamente por darle a Lotario «tan presto la entera posesión de su voluntad», a lo que la perspicaz Leonela responde:

"el amor, unas veces vuela y otras anda; con éste corre, y con aquél va despacio; a unos entibia, y a otros abrasa; a unos hiere y a otros mata [...] $Y$ siendo así, ¿de qué te espantas, o de qué temes, si lo mismo debe de haber acontecido a Lotario, habiendo tomado el amor por instrumento de rendirnos la ausencia de mi señor? [...] Porque el amor no tiene otro mejor ministro para ejecutar lo que desea que es la ocasión: de la ocasión se sirve en todos sus hechos, principalmente en los principios» ${ }^{5}$.

Estas razones tranquilizan a Camila, pero sirviéndose de Leonela como confidente quedará empañada en breve su discreción (máxima virtud femenina para nuestro autor llevado a su extremo en el espléndido personaje de Dorotea), pues como avisa Cervantes, «los descuidos de las señoras quitan la vergüenza a las criadas», similar a esta otra reflexión de un personaje calderoniano: «icuántas famas / las criadas vendieron de sus amas!» (Con quien vengo vengo).

Para que no decaiga la perplejidad que pueda ocasionar el «caos» que algo «tiene de imposible» como señalaba el cura, se produce la transformación de Lotario en un amante celoso al ver salir a otro hombre de la casa de Camila (que era realmente el amigo de Leo-

5 Miguel de Cervantes, Don Quijote de la Mancha, Ed. de John Jay Allen. Madrid, Cátedra, 1994, vol. I, p. 417. 
nela). Se siente engañado y sin pedir explicaciones a Camila, acude por despecho a contárselo a Anselmo al que aún estaba ocultando el adulterio consumado. Cuando Lotario confiesa el embrollo a Camila y ésta esclarece los hechos, se arrepiente de su comportamiento pero, como «naturalmente tiene la mujer ingenio más que el varón», afirma Cervantes, será Camila la que intente salir bien de tal laberinto.

No olvidemos que el ingenio, o perspicacia, en un mundo rodeado de apariencias es la facultad más valorada por el hombre del siglo XVII. Camila, así como Clara en la comedia calderoniana El agua mansa, e igualmente Laureana y Clavela, protagonistas de la Historia exemplar de las dos constantes mugeres españolas (1635) de Luis Pacheco de Narváez, nos vienen a demostrar que el ingenio es una facultad generadora, «crea» - como dice Calderón- lo que engaña a los ojos.

En la representación teatral que Camila, con la ayuda de Leonela y la complicidad de Lotario, idea para demostrar su virtud, y que miraba Anselmo, "cubierto detrás de unos tapices donde se había escondido", aparece ya el tema barroco del engaño de los sentidos ${ }^{6}$.

Desde el momento que la identidad del personaje depende de cómo éste es visto y de su confrontación ante la versión que el otro percibe de él, la dialéctica de miradas que utiliza Camila le proporciona un gran valor dramático, le dice a Lotario:

"¿con qué rostro osas parecer ante quien sabes que es el espejo donde se mira aquél en quien tú te debieras mirar, para que vieras con cuán poca ocasión le agravias?».

La vista le revela a Anselmo que no hay tal agravio a su honor por parte de Camila, él fue «el fabricador de su deshonra» como confiesa antes de morir.

«Dícese que aunque se vio viuda (Camila), no quiso salir del monasterio" donde se había retirado. De nuevo la mujer ejerce su libertad y cambia su destino al renunciar libremente a esa misma libertad.

Cuando recibe noticias de la muerte de Lotario profesa y muere en breves días a manos de la melancolía. Cervantes escoge este final trágico para una novela ejemplar de tan «desatinado principio».

Situémonos ahora en el año de 1635, cuando se publica una novela de Luis Pacheco de Narváez, Historia exemplar de las dos

- María Alicia Amadei-Pulice, "La perspectiva y el teatro barroco», en Calderón y el Barroco. Exaltación y engaño de los sentidos. Amsterdam-Philadelphia, John Benjamins Publishing Company, 1990, p. 111. 
constantes mvgeres españolas, en la que Calderón le dedica un soneto donde alaba que quede engrandecida la virtud del sexo femenino ${ }^{7}$.

Se nos presentan otras dos mujeres con la libertad personal anulada y que sufren por diferentes causas el abandono de sus maridos.

Alexandro, marido de Laureana, ha de salir de viaje para cobrar la herencia de un tío de su mujer, fallecido en las Indias, y que se encuentra depositada en la Casa de Contratación de Sevilla.

Antes de partir aconsejaba así a Laureana:

"[...] el cuidado en cerrar puertas, y ventanas, advertida de su prudencia, que aún la entrada del Sol, estando el marido ausente, pone a peligro la fama, la moderación en las galas, reduciéndolas a un hábito decente, por ser éstas los más ciertos registros del poco, o mucho sentimiento en lo libre de la soledad; el gusto de que todos los de su familia le refiriesen perfecciones de su Alexandro; el no recibir visitas aun de los cercanos parientes, y con dificultad, y veces muy raras las de solo un hermano que tenía; la ordinaria asistencia en su oratorio, donde pasaba la noche y la hallaba el día; la templanza en el común sustento, que es lo que también descubre si a una mujer le es, o no agradable la libertad».

Alexandro, instalado ya en Sevilla, ve desde su balcón que en el de enfrente se asoma una bella mujer, se trata de Clavela, de quien se enamora.

Pacheco, igual que Calderón y tantos de sus contemporáneos, declara a la vista el sentido principal, y por ello los personajes de

7 Historia exemplar de las dos constantes mvgeres españolas. Por Don Luis Pacheco de Narvaez, Maestro del Rey nuestro Señor en la Filosofía y destreza de las Armas, y Mayor en todos sus Reynos. A la Señora Doña Catalina Chacon y Rojas, muger de don Iuan Ramírez Fariña, Cauallero de la Orden de Santiago, Cauallerizo de Su Magestad, y su Corregidor en la Ciudad de Ezija. En Madrid, en la Imprenta del Reyno, año 1635. (Trabajamos con el manuscrito que se conserva en Houghton Library de Harvard University).

La quinta dedicatoria corresponde al Soneto de don Pedro Calderón de la Barca:

Si por la espada es inmortal la gloria,

Si por la pluma es la ambición divina,

Bien uno y otro genio te destina

Del tiempo, y del olvido la vitoria.

Bien (Luis) pues de Felipe la memoria Deve a tu docta espada su doctrina, Bien pues deve la luz de Catalina Diestra a tu pluma la exemplar historia.

Si varones constantes enseñaste, Si Constantes Mugeres escriuiste, Eterno un sexo y otro te perfuma;

Aquel por la destreza que inuentaste, Este por la virtud que engrandeciste, Tomando, ora la espada, ora la pluma. 
su novela, como los de la comedia calderoniana, exploran la dialéctica de las miradas.

Volviendo a nuestro personaje, Alexandro, éste se apoya en el parecido de Laureana y Clavela para justificar su inminente adulterio, argumentando lo siguiente:

"Si con atención miro el suyo (rostro), perfectísimamente veo el vuestro, y en la tan igual como milagrosa semejanza, amo a los dos en uno, porque en cada uno están los dos, ¿a quién le fue posible amar el retrato, y aborrecer el original? [...] verdad será el decir, que cuanto más amare a Clavela, os estaré amando más».

Conseguir que se rinda Clavela no será tarea fácil como le indica Claudina - su criada y de la que se harán esclavos Alexandro y más tarde la misma Clavela-, pues es mujer casada y admirada por su hermosura en Sevilla, y aunque su marido falta demasiado de su casa, Clavela está entre sus propiedades. Alexandro sigue los consejos de Claudina en el arte de amar, como son constancia, gentilezas exteriores, grandeza de entendimiento, gallardía y viveza de ingenio, "corta lengua, y largas manos» y, finalmente, "las riquezas en el hombre gastadas con generosidad, son como la blancura en la mujer, de quien dicen, que encubre sesenta y dos faltas».

Tópicos todos que lectores de ambos sexos oían constantemente, también, en los escenarios teatrales de la época.

Al fin Clavela se entrega y cuando Alexandro se encuentra con ella en sus aposentos el marido les descubre; Clavela se tira por el balcón y el marido cree que ha muerto, aunque no es cierto, pues recuperado el sentido huye disfrazada de hombre con Alexandro.

Marcelo queda desconcertado por la supuesta muerte de su esposa y su criado le recuerda:

"Cuántas veces os previno mi advertencia, ser peligrosa la falta de un marido en su casa; porque dejar a una mujer en la lozanía de la juventud, ofendida con dilatadas horas de soledad, quejosa con la aspereza del trato, haciendo desprecio de su belleza, mal pagada con la deuda del matrimonio [...] hace reventar el más constante sufrimiento. Y también os advertí que aquél que de ordinario solicita casas ajenas, deja en desamparo la suya, y al más confiado le suelen pagar en la propia moneda».

Pacheco, autor de esta amena novela, lanza el aviso ejemplar y busca un final feliz: Laureana cuando llega a Sevilla para constatar por sí misma el engaño de su marido, se enamora de Marcelo, supuestamente viudo de Clavela.

De nuevo vence el amor, como forma suprema de la libertad y otro autor dota de especial ingenio a sus protagonistas femeninas para que puedan elegir su destino. 
Para finalizar, nos detendremos un momento en la comedia calderoniana ${ }^{8}$, donde los personajes femeninos sobrepasan en muchas ocasiones a los varones en inteligencia y chispa; de un acto al siguiente pueden transformarse de sumisas en activas y tomar el destino en sus propias manos.

El caso de las hermanas Clara y Eugenia, protagonistas de $E l$ agua mansa ${ }^{9}$, una comedia de capa y espada con un asunto típico del marco genérico al que pertenece y con un elemento, Don Toribio, el figurón, que le proporciona un cariz realmente cómico ${ }^{10} \mathrm{a}$ la obra, completa nuestra reflexión.

Clara y Eugenia abandonan el convento donde estaban recogidas desde la muerte de su madre, para trasladarse a Madrid donde les espera su padre, don Alonso, que ha regresado de Méjico. Su principal objetivo es prepararles casamiento, por supuesto, mirando por los intereses del patrimonio familiar más que por la felicidad de unas hijas a las que desconoce. Será Mari-Nuño, la dueña, quien le informe:



(vv. 149-154)

De doña Eugenia dice:

$$
\begin{aligned}
& \text { Su condición es terrible; } \\
& \text { no se vio igual desagrado } \\
& \text { en mujer; dirá señor, } \\
& \text { una pesadumbre a un santo. } \\
& \text { Es más soberbia y altiva, } \\
& \text { tiene a los libros humanos } \\
& \text { inclinación, versos hace... }
\end{aligned}
$$

8 Sobre el tipo de sociedad que reflejan estas comedias, donde el deseo puede triunfar, vid. MARÍA Grazia PROFETI, "Comedia al cuadrado: Espejo deformante y triunfo del deseo", LUCIANO GARCía LORENZo, ed., La comedia de capa y espada. Cuadernos de Teatro Clásico, núm. 1. Madrid, Compañía Nacional de Teatro Clásico, 1988, pp. 51-60.

9 Pedro CALDERÓN de la BARCA, El agua mansa. Guárdate del agua mansa, ed. crítica de las dos versiones por IGNACIO ARELlano y Víctor GARCía Ruiz. KasselMurcia, Reichenberger-Universidad de Murcia, 1989.

10 Vid. Ignacio ARELlano, "La comicidad escénica», Convención y recepción. Estudios sobre el teatro del siglo de oro. Madrid, Gredos, 1999, pp. 264-307. 
Ello le basta a don Alonso para decidir, en contra de la norma, que sea la pequeña Eugenia «primera en estado /que el marido y la familia son los médicos más sabios / para curar lozanías».

Es decir que si la vital Eugenia tenía alguna esperanza de gozar durante un tiempo de su libertad en la corte, pronto se desvanecerá.

El padre les informa de la llegada de su sobrino don Toribio, mayorazgo pobre de su casa de Cuadradillos, para casarlo con una de ellas y hacerlo heredero del patrimonio familiar. La presentación del montañés es desastrosa y la reacción de las hermanas imaginándoselo de esposo es la siguiente:

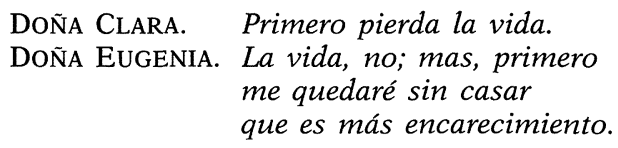

(vv. 813-816)

Mientras, en la casa de su vecino, don Félix, que vive cómodamente, sin idea de complicarse la vida con temas del corazón, tiene noticia por su criado de las dos nuevas damas:

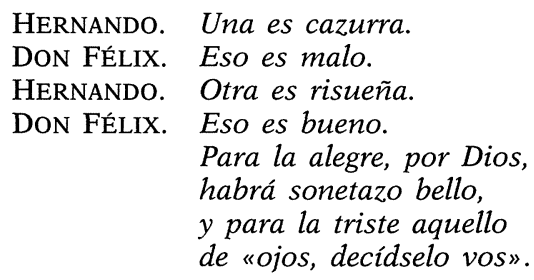

(vv. 259-264)

Dos amigos, don Juan y don Pedro, invitados de don Félix, participan con éste desde el balcón de la visión de Clara y Eugenia. Don Juan y don Pedro reconocen a Eugenia asombrados, pues ambos la han estado cortejando sucesivamente.

Los dos (que ignoran su coincidencia amorosa) piden por separado ayuda a don Félix. Éste se muestra dispuesto, ya que planea servir a la que dejen libre, negándose al matrimonio, sólo por simple pasatiempo.

Al fin, los tres galanes se cruzan con las damas, y al intentar identificar don Félix a la amada de sus amigos se confunde, pues ellas han intercambiado el pañuelo (que es la seña indicada).

Engañado y dispuesto a ser amigo leal, don Félix renuncia a la que más le atraía (Clara, a quien él cree Eugenia) y se dispone a cortejar a la otra, Eugenia (pensando que es Clara). 
Mientras, don Alonso ya ha concedido la mano de su hija Eugenia a don Toribio.

Tras los errores de don Félix en la identificación, provoca un nuevo enredo al llevar un billete para Eugenia y entregárselo a Clara, como era natural siguiendo su criterio equivocado.

La lectura del billete ajeno por Clara abre el acto III y en ese momento comienza a producirse la transformación de esta mujer, «agua mansa» en «ruidosa», pues ella misma dice:

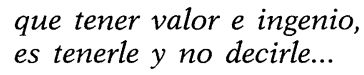

La vanidad de Clara queda herida cuando descubre el cerco amoroso alrededor de su hermana. Asustada Eugenia y sin iniciativas, cambia de conducta y decide despedir a sus dos amantes, pero éstos, impulsados por amor y celos no cesan en su empeño: los dos consiguen introducirse en la casa y desde su escondite presencian la declaración de don Félix a Eugenia (Clara para él) con el consiguiente desafío de los dos galanes furiosos.

En ese punto es donde Clara, que libremente ha encauzado ya su destino, aprovechando su ingenio le permite ser ella quien domine la situación: saca a don Toribio al balcón para que no estorbe, engaña a Eugenia encerrándola en su cuarto para quedarse a solas con don Félix, y cuando está a punto de aclararse el enredo, llega don Juan, aparece don Pedro amenazando a Toribio y terminan todos reunidos en la sala. Pasado el momento de confusión y enfrentamiento se aclaran las identidades y se conciertan los matrimonios de don Félix con Clara y de Eugenia con don Juan.

Ambas han conseguido la liberación de sus sentimientos para alcanzar la felicidad.

A través de esta galería de personajes femeninos, no podemos negar que Cervantes, Calderón y Pacheco se adelantan a una concepción liberal de la mujer. Esta mujer no se hunde en la frustración, ni realmente su situación es trágica (como la que retrata Lorca, por ejemplo), la que retratan los autores citados es una mujer que, entre la sumisión y la astucia obra conforme a sus intereses para encontrar un resquicio de libertad en una sociedad represiva, gracias al ingenio que les permite confundir a cuantos las rodean. 